\title{
Patience is a virtue -- in value investing
}

DOI:

10.1111/irfi.12251

\section{Document Version}

Accepted author manuscript

Link to publication record in Manchester Research Explorer

\section{Citation for published version (APA):}

Schenk-Hoppê, K. R., \& Hens, T. (2018). Patience is a virtue -- in value investing. International Review of Finance. https://doi.org/10.1111/irfi.12251

\section{Published in:}

International Review of Finance

\section{Citing this paper}

Please note that where the full-text provided on Manchester Research Explorer is the Author Accepted Manuscript or Proof version this may differ from the final Published version. If citing, it is advised that you check and use the publisher's definitive version.

\section{General rights}

Copyright and moral rights for the publications made accessible in the Research Explorer are retained by the authors and/or other copyright owners and it is a condition of accessing publications that users recognise and abide by the legal requirements associated with these rights.

\section{Takedown policy}

If you believe that this document breaches copyright please refer to the University of Manchester's Takedown Procedures [http://man.ac.uk/04Y6Bo] or contact uml.scholarlycommunications@manchester.ac.uk providing relevant details, so we can investigate your claim.

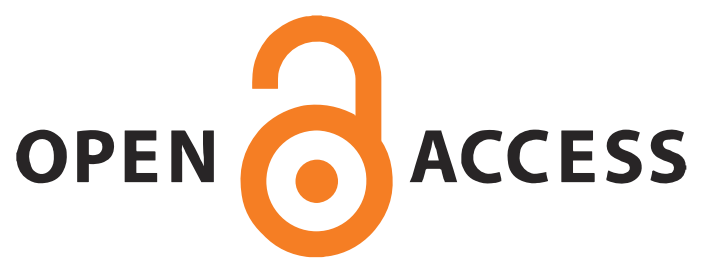




\title{
Patience is a virtue - in value investing*
}

\author{
Thorsten Hens ${ }^{a}$ and Klaus Reiner Schenk-Hoppé ${ }^{b}$
}

October 27, 2018

\begin{abstract}
This note illustrates a simple but important insight for financial investment. In a heterogeneous agent-based evolutionary finance market model with long-lived assets, markets are stable if clients of fundamental ('value') investment funds are more patient than clients of other funds.
\end{abstract}

Keywords: Financial market stability; delegated fund management; investor patience; agent-based modeling; evolutionary finance.

\section{Introduction}

Recent stock market crashes have made market stability a central topic of investors and policy-makers alike, asking for advice from academia. However, academic research is divided about the cause of these severe mispricings. In particular the importance of the heterogeneity of investors is debated. While Franke and Lüders (2010) show that in traditional rational expectations models heterogeneity of investor preferences decreases market stability, behavioral finance models like those outlined in Shiller (1999) and Shleifer (2000) show that irrational investors (e.g., trend chasers or noise traders) cause instability and mispricing. This diversity-stability debate in finance is akin to biological models of interacting species (McCann, 2000). In this note we show that in a standard heterogeneous agent financial market model mispricing is smaller if fundamental investors are more patient than other investors. Thus within this model the diversity-stability debate comes to the same conclusion as the behavioral financial market models.

Patience is widely praised as one of the keys to investment success (and impatience as the main source of failure) in investment books such as Burton G. Malkiel's (2016) A Random Walk down Wall Street: The Time-tested Strategy for Successful Investing (first published in 1973 and currently in its $11^{\text {th }}$ edition) or The Little Book of Common Sense Investing by John C. Bogle (2007), the father of index-investing.

Heterogeneous agent models of financial markets (HAMs) however build on the premise that all investors are equally patient (or impatient). Their willingness to move their capital between investment styles depends only on differences in realized performance; see the

\footnotetext{
*Financial support by the URPP Finreg of the University of Zurich is gratefully acknowledged.

${ }^{a}$ Swiss Finance Institute, Department of Banking and Finance, University of Zurich and Faculty of Economics and Management, University of Lucerne, Switzerland and Department of Finance, NHHNorwegian School of Economics, Norway. E-mail: thorsten.hens@bf.uzh.ch.

${ }^{\mathrm{b}}$ Department of Economics, School of Social Sciences, University of Manchester, United Kingdom, and Department of Finance, NHH-Norwegian School of Economics, Norway. E-mail: klaus.schenkhoppe@manchester.ac.uk.
} 
seminal work on theoretical modeling by Hommes (2013); Hommes and Wagener (2009), and recent applied studies, e.g., Grazzini et al. (2017); Kukacka and Barunik (2017), Coqueret (2017), and Assenza et al. (2017).

Evolutionary finance models (Evstigneev et al., 2006, 2009, 2016) in contrast are populated by investors who are infinitely patient; they never move any money between funds. In these models, value investment dominates the market in the long-run and prices are equal to fundamental values. Here we ask how the market dynamics changes when investors' choice of style and their degree of patience correlates. We are particularly interested in the case when fundamental value investors have the greatest patience of all.

The motivation for this line of inquiry is two-fold. First, there is evidence that in practice average holding periods depend on the type of fund investors are invested in. Shareholders in Berkshire-Hathaway (a self-declared value investor) are astonishingly patient: According to NYSE data, the annual turnover of this stock is around $10 \%$ p.a. compared to about $80 \%$ for the average stock. Roberge et al. (2013) report that holding periods of investment managers of equity mutual funds also vary considerably across Morningstar's equity categories: For instance the average holding period of large value stocks is 2-3 times longer than that of technology stocks. Our paper analyzes whether such differences in investor patience matter.

Second, value investors are commonly seen as making markets more resilient as buyers (and sellers) of last resort (Harris, 2015, p. 8). However, the interplay between different styles can potentially weaken this argument. Noise traders can generate, by chance, shortterm momentum which might be amplified by trend-chasers. With a sufficient inflow on capital, fundamental traders can be overwhelmed. In this sense fundamental traders can do poorly whilst noise traders 'create their own space' simply through differences in investor patience. We seek to answer how patient value investors have to be in order to perform the moderating, last-resort function well.

The model analyzed in this note captures the impact of investor patience (or impatience) on the flow of funds between different styles in the simplest possible way. Our aim is not to produce the most 'realistic' model but a parsimonious one in which the main point can be made most succinctly.

\section{Model}

We consider a heterogeneous agent financial market model that is based on Palczewski et al. (2016) but permits clients of funds to differ with respect to their degree of patience. This feature is implemented as a fund-specific flow participation. The flow participation is the percentage amount of capital that leaves a specific fund (relative to the value of total assets under management). The total gross outflow of capital is re-allocated according to performance using a discrete-choice model as in the standard HAM. When the flow participation of a fund is high, investors in this style are inherently less patient than 
investors in a fund with a low flow participation.

The major change to the model in Palczewski et al. (2016) is to replace the parameter $\beta$ (which the fraction of capital retained by each fund) by fund-specific fractions $1-\pi^{i} \in$ $[0,1] .{ }^{1}$ Here $\pi^{i}$ measures the degree of patience of a fund $i$ 's clients. Only the proportion $1-\pi^{i}$ of fund $i$ 's investments is allocated according to some performance measure in every time period. Less (more) patient clients reallocate a larger (smaller) proportion of their investment in every period. The money pulled out of the current fund is moved to other funds according to differences in performance. For style $i, \pi^{i}$ denotes the (constant) proportion of wealth that stays with the fund where it is currently invested. The two polar cases of fund flows are the evolutionary finance case where all clients are infinitely patient $\left(\pi^{i}=1\right)$ and the HAM case where all clients are infinitely impatient $\left(\pi^{i}=0\right)$. One finds the random dynamical system (using the notation in Palczewski et al. (2016))

$$
\begin{aligned}
V_{t+1}= & {\left[\operatorname{Id}-(1-c) \Theta_{t} \Lambda_{t+1}\left(\operatorname{diag}(\pi)+q_{t}(\mathbf{1}-\pi)^{T}\right)\right]^{-1} \times } \\
& {\left[\Theta_{t} D_{t+1}+(1+r)(1-c) \operatorname{diag}\left(\lambda_{t, 0}\right)\left[\pi \circ V_{t}+q_{t-1}(\mathbf{1}-\pi)^{T} V_{t}\right]\right] }
\end{aligned}
$$

Parameter specification. The simulated model contains one risky and one risk-free asset with net return $r$. Dividends are i.i.d. with truncated normal distribution $\mathcal{N}(\mu, \sigma)^{+}$ and mean $\bar{D}$. There are three funds: fundamental, trend-chasing and noise trading that are defined exactly as in Palczewski et al. (2016). We set $r=0.1 \%$ (corresponding to $5.3 \%$ p.a. if each time step is interpreted as one week), $c=r /(1+r), \bar{D}=1, \sigma=20 \%$, $L=30, \alpha^{L}=L, \alpha^{F}=0.25, \alpha^{N}=1, \delta=0.97, \epsilon=0.2, \gamma=2$ and $\rho=0.95$.

Clients of the fundamental fund have the degree of patience $\pi^{F}$ which is varied between the values $100 \%$ (complete patience, all capital stays with the current fund and thus never withdrawing any capital, i.e., the standard case considered in evolutionary finance), 99\%, $95 \%, 90 \%, 75 \%, 50 \%, 25 \%$, and $0 \%$ (withdrawing all capital in every period, i.e., the value of assets under management at the fundamental fund depend only on realized performance which is the standard case considered in HAMs). Clients of the trend-chaser and the noise fund have the same degree of patience $\pi^{T}=\pi^{N}$.

\section{Results}

The long-run market dynamics for different degrees of fund-specific client patience is evaluated along several dimensions. The first aspect is the average share of the market, i.e., the relative amount of assets under management, held by each of the three funds in the long-run. This information will provide insights into the market ecology: which funds are viable and co-exist and which funds end up being negligible. The second aspect is difference in portfolios. Although funds' investment styles may look different ex-ante, asset prices can lead to a situation where portfolios are collinear (i.e., are linear versions

\footnotetext{
${ }^{1}$ See the working paper version https://ssrn.com/abstract $=3146848$ for details.
} 


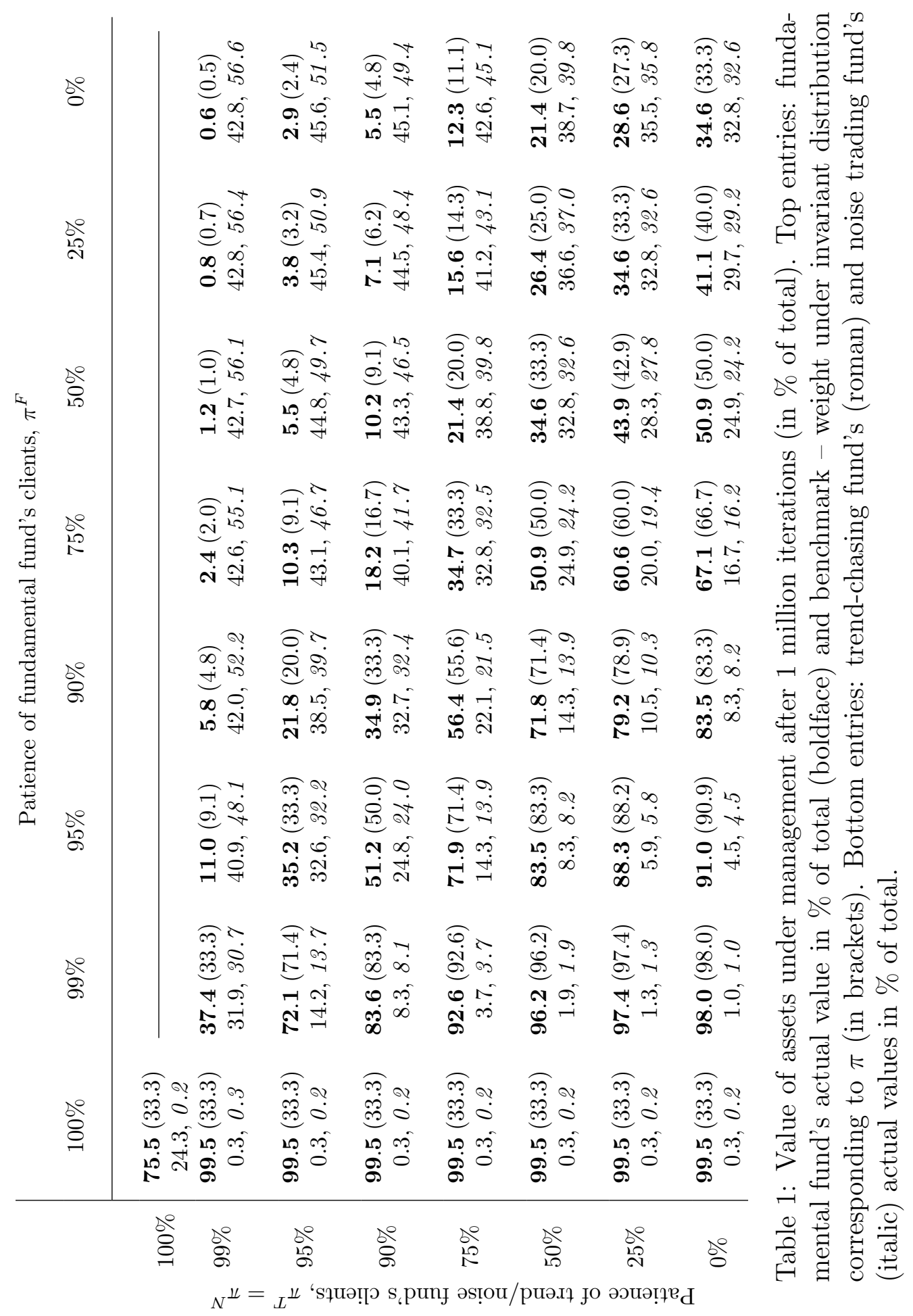

of each other). The third aspect relates to mis-pricing where we ask how far (if at all) the risky asset's price deviates from its fundamental value. This provides insights into the efficiency of the market.

Performance. The long-run distribution of wealth under management across the three style for varying degrees of patience is provided in Table 1. Each entry consists of four numbers; two numbers in each of the two lines that constitute the entry: In the first line, the long-run proportion of wealth held by the fundamental fund (boldface) and its benchmark, the weight under the invariant distribution corresponding to $\pi$ 's (in 
brackets). The invariant distribution gives equal weight to the trend-chasing fund and the noise trading fund as both funds' clients are equally (im)patient (calculated as half of the residual weight). The second line contains the trend-chasing fund's (roman) and the noise trading fund's proportion of total wealth (italic). The benchmark for the fundamental fund is the percentage of assets that would prevail on average if there were no systematic gains from or losses to the rival styles. The data are collected after 1 million periods and show virtually no variation across runs, hence confidence intervals are not reported.

The first row contains only one entry as all the other cases in this row are identical to the evolutionary finance model without performance-driven flow of assets $\left(\pi^{F}=\pi^{T}=\right.$ $\pi^{N}=1$ ) because only funds with patience less than 1 participate in the flow of money. Hence there is no outflow from the fundamental fund as long as $\pi^{T}=\pi^{N}=1$.

The most striking observation is that the fundamental fund does not have fewer assets under management than under the benchmark in any of the cases analyzed. When fundamental fund investors are infinitely patient (first column), they make considerable gains at the expense of the other funds. It does not matter how impatient are the clients of the trend-chasing and the noise trading fund: they lose $99 \%$ or more of their initial wealth to the fundamental fund. Only when all investors are infinitely patient, the trendchasing fund loses merely a third of its initial wealth to the fundamental fund while the noise trading fund loses more than $99 \%$ of its initial wealth.

When fundamental fund investors are very patient but not infinitely so (second column where the fundamental fund's clients reallocate $1 \%$ of their assets according to realized performance), the gains over the benchmark can be extremely small. However in these cases the benchmark is high with proportions between $83.3 \%$ and $98.0 \%$ of the market wealth which makes it harder to exceed than the $33.3 \%$ benchmark in first column.

Lower degrees of patience are detrimental to investment success. This is true for all styles. Fix any degree of the fundamental fund's style (i.e., pick any column), then the assets under management of trend-chasing and noise trading fund decrease when their impatience increases. The same is true along rows. The more impatient are clients of the fundamental fund, the lower the fund's assets.

The main lessons from Table 1 are that fundamental investors do the better the more patient they are, fundamental investors do better the more impatient are the other investors, and trend-chasing and noise trading funds perform quite similar.

A different perspective is to look at the data in terms of survival/extinction and coexistence of funds. Extinction of the noise trading fund is observed when the fundamental fund is perfectly patient. If, in addition, the trend-chasing fund is not perfectly patient, then it also becomes extinct. The market selects for the patient fundamentalists. If all funds' clients exhibit impatience, then all of the investment styles co-exist.

All clients being perfectly patient (the case studied in the evolutionary models cited above) gives rise to a very slow process of market selection which eventually will see the fundamental fund prevailing. After 1 million time periods, noise trading is almost extinct 
but the trend-chasing fund still commands $24.3 \%$ of all wealth invested. This amount decreases over time but at a decreasing rate. The conjecture is that the trend-chasing fund 'imitates' the portfolio choice of the fundamental fund (which happens, for instance, when asset prices are constant). This issue will be studied later. The observation that noise trading is doing well, except when the fundamental fund's clients are very patient, gives rise to the conjecture that the market can be inefficient. A point that will also be explored in detail later.

The combination of impatient clients and different investment styles enables the noise trading fund to survive. The fund's allocation creates noise that, by chance, can generate a small amount of momentum. This momentum is then amplified by the trend-chasing fund which, in turn, benefits the performance of the noise trading fund as it is overweight in the asset that experiences price momentum. The finding highlights that momentum, randomly initiated by noise traders, can ensure the survival of noise traders. Since the three funds in the model do not have a notion of risk, noise traders have to 'create their own space' differently to the mean-variance world.

Asset allocation. Since the investment styles are dynamic through their dependence on past prices - and thus look quite different ex ante - it is of interest to ask whether they are distinct ex post, i.e., whether funds' actual portfolio holdings differ.

We measure the difference between the portfolios of two funds as the relative difference of the proportion of the funds' investments in the risky asset. If this difference is small then the funds' portfolios are approximately collinear and funds effectively make the same investments. Table 2 reports this measure for the trend-chasing fund vs the fundamental fund. The top entry in each cell is an average of $\left(\lambda_{t, 1}^{T}-\lambda_{t, 1}^{F}\right) / \lambda_{t, 1}^{F}$ (reported in percentages) over 10,000 time periods and 100 independent runs. The bottom entry in each cell is the $90 \%$ confidence interval (also in \%).

The first observation is that the portfolios of the trend-chasing and the fundamental fund are quite similar when averaged over time. When the fundamental fund's clients are more patient, the trend-chasing fund tends to be overweight (on average) in the risky asset (lower left corner of Table 2). If, on the other hand, the clients of the trend-chasing fund are more patient (but not infinitely patient), its exposure to the risky asset is typically lower than that of the fundamental fund (upper right corner, excluding top row).

There is considerable variation across samples. The $90 \%$ confidence intervals (bottom entries in each cell) show that the trend-chasing funds exposure to the risky asset is changing considerably over time. For instance, when all clients are equally (im)patient (which corresponds to the down diagonal of the table), the trend-chasing fund's exposure to the risky assets with $10 \%$ probability will either be $30 \%$ less or $60 \%$ higher than that of the fundamental fund.

The most stable portfolio allocations (i.e., least cross-sectional variation) are observed when the fundamental fund's clients are extremely patient $\left(\pi^{F}=99 \%\right)$ and the other funds' clients are less patient. In fact the more impatient noise and trend-chasing clients 


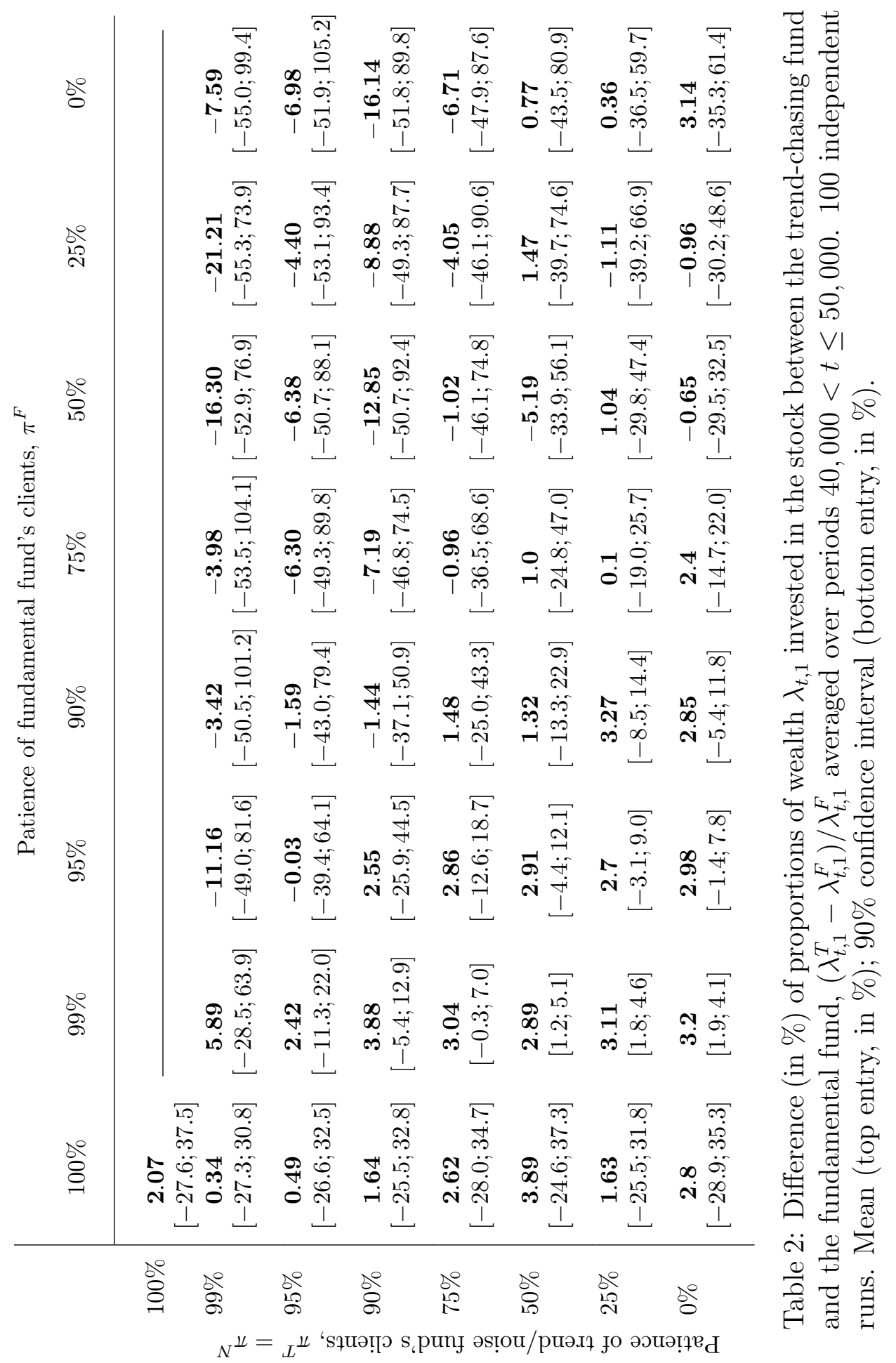

are, the more stable the portfolio allocation of the latter fund.

Large deviations in investment proportions over time seem to coincide with large market shares of the noise trading fund. To test this conjecture, we regress the length of the confidence interval on the noise trading fund's average proportion of wealth under management. It turns out that more than $75 \%$ of this variation is explained by the relative size of noise trading. This finding implies that short-term trends, initiated randomly by the actions of the noise trading fund, can be amplified by the trend-chasing fund's 


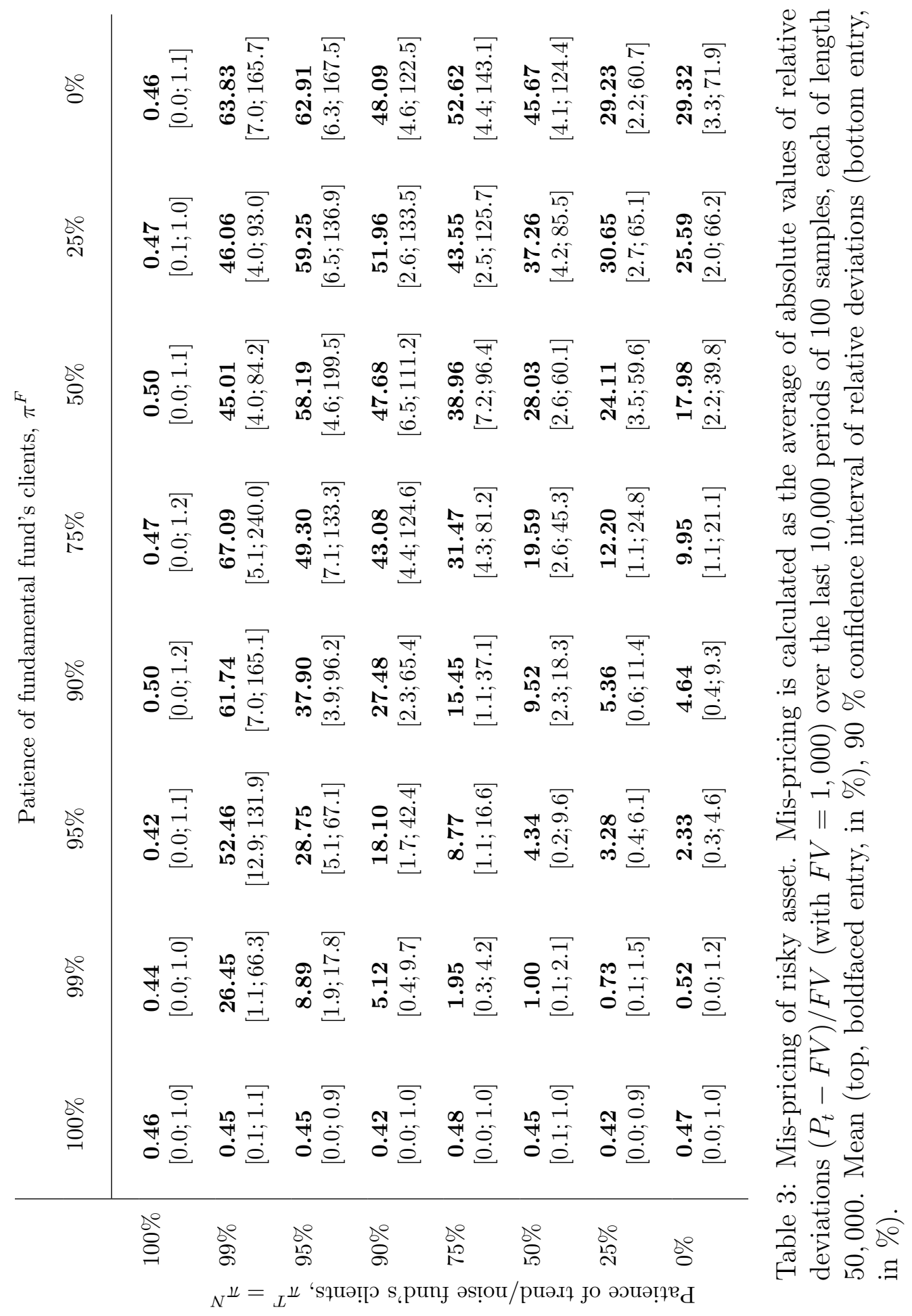

strategy. In the medium term the trend is maintained by luring clients of other funds into transfering wealth due to the (unrealized) excess returns through capital gains. In the longer term, the momentum fades and clients desert the fund.

Interestingly, the trend-chasing fund's position can be the more extreme, the more patient are the trend-chasing and noise trading funds' clients. (Range of the confidence intervals are increasing along rows.) By attracting capital from more impatient clients of the fundamental fund, outperformance can last the longer.

Mispricing. We finally ask to what extent the funds' portfolio choices impact asset 
prices. The actual price dynamics is related to these decisions through the value of assets under management. Extreme allocations only lead to an inefficient market, if the fund is sufficiently large.

Table 3 reports the difference between the market price of the risky asset and its fundamental value relative to the latter. Mispricing is formally defined as $\left|\left(P_{t, 1}-F V\right) / F V\right|$ with the fundamental value $F V=1,000$. To capture systematic rather than short-term mispricing, we average realizations of this variable over the last 10,000 time periods of runs of length 50,000. The table reports both the mean over 100 independent runs and the $90 \%$ confidence interval for each combination of degrees of patience.

Asset prices are close to their fundamental value as long as the clients of the fundamental fund are more patient than those of the other funds. Mean mis-pricing in the lower-left corner of Table 3 is less than $10 \%$ in almost all cases. There is however some variation between samples. If the fundamental fund's clients degree of patience is $95 \%$ but that of the other funds' only $75 \%$, then the risky asset is mis-valued by at least $16.6 \%$ for $5 \%$ of the time. The most extreme mis-pricing and the most volatile prices are observed when $\pi^{F}=0$.

The mean of the noise trading fund's market share explains about $92 \%$ of the size of the confidence interval and thus the likely range of mis-pricing observed. Thus the existence of the noise generated by the noise trading fund is the primary source of mispricing. However, time series volatility of the risky asset's price is (averaged across all cases) more than twice that of the noise trading fund's contribution $\left(\lambda_{t, 1}^{N} W_{t}^{N}\right)$. The second source is the amplification of small price movements caused by the trend-chasing fund.

Figure 1 illustrates these findings. It shows a simulation run for varying degrees of the fundamental fund clients' patience $\pi^{F}=99 \%, 75 \%$, and $25 \%$ with the patience of the other two fund's clients fixed at $\pi^{T}=\pi^{N}=25 \%$. For reference, the investment strategy of the noise trading fund and the dividend payments are identical across the three scenarios.

When the fundamental fund's clients are very patient, panel (a), price volatility is negligible despite the noise trading fund varying its exposure to the risky asset over time. The reason is provided in the Table 1 which shows that the fundamental fund owns 97.4\% of all assets. Hence neither the noise trading nor the trend-chasing fund have any market impact. As reported in Table 2, the trend-chasing fund effectively imitates the fundamental fund's asset allocation.

Lower patience, $\pi^{F}=75 \%$, panel (b), leads to higher price volatility. This volatility is caused by both the noise trading and the trend-chasing fund. We observe that the noise trading fund leads and the trend-chasing fund follows after the price has moved away from the risky asset's fundamental value. In this scenario the fundamental fund still holds $60.6 \%$ of the market wealth on average while the remainder is almost identically split between the other two funds. Table 2 finds that the trend-chasing fund is underweight in the risky asset by $19.0 \%$ or overweight by 25.7 or more (relative to the fundamental 

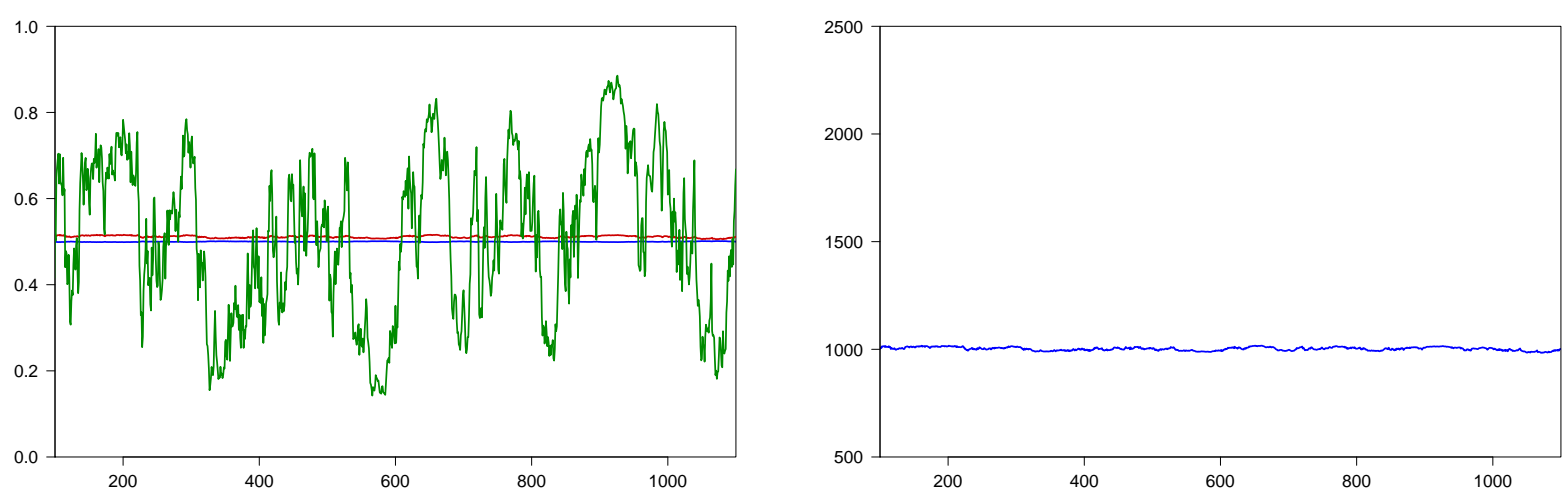

(a) $\pi^{F}=99 \%$ and $\pi^{T}=\pi^{N}=25 \%$
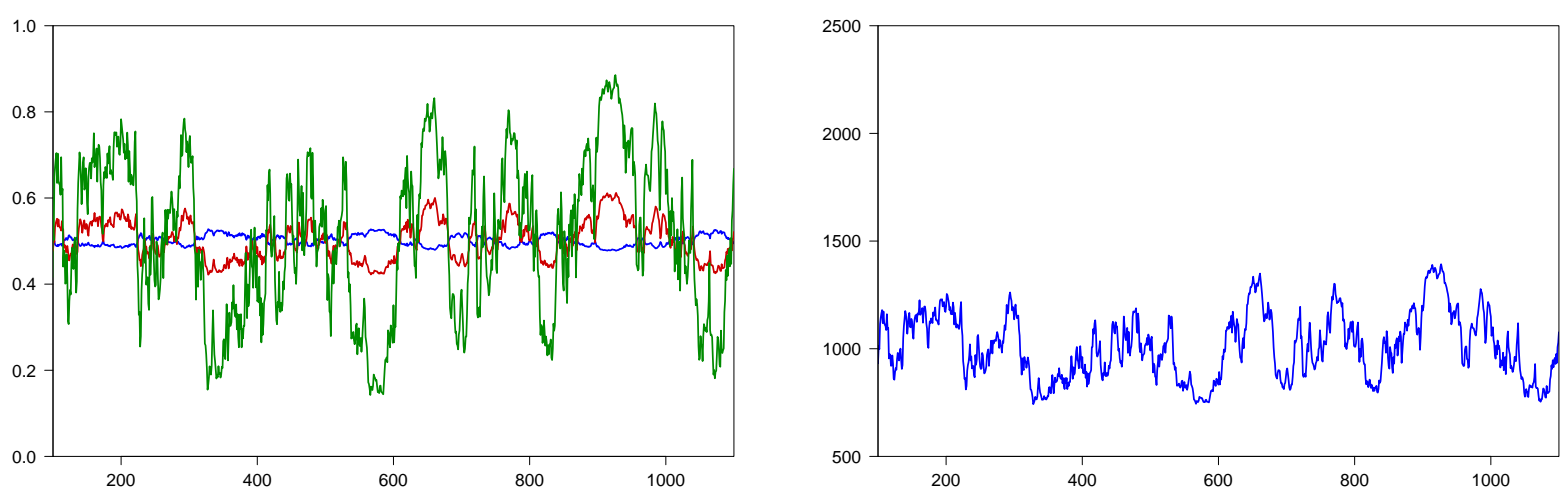

(b) $\pi^{F}=75 \%$ and $\pi^{T}=\pi^{N}=25 \%$
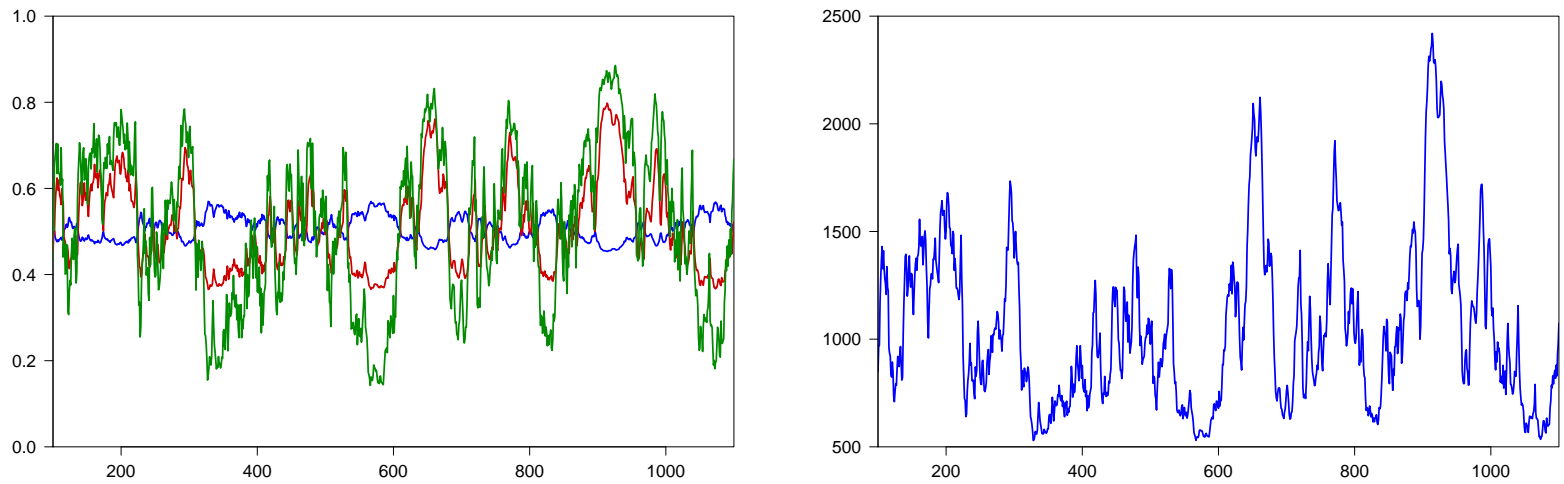

(c) $\pi^{F}=25 \%$ and $\pi^{T}=\pi^{N}=25 \%$

Figure 1: Simulation run of 1,000 time periods. Left panels: Proportion of wealth invested in the risky asset, fundamental fund (blue), trend-chasing fund (red), and noise trading fund (green). Right panels: Price of the risky asset. The degree of patience of trendchasing and noise trading fund are fixed at $\pi^{T}=\pi^{N}=25 \%$. In all graphs, the same random path for noise trading fund's strategy (which is independent of price) is used. 
fund) for $10 \%$ of the time.

Impatience of the fundamental fund's clients, $\pi^{F}=25 \%$, panel (c), entails extreme mis-pricing. According to Table 3, 5\% of the time the asset is mispriced by at least $65.1 \%$. In conjunction with price movements, we observe pronounced (pro-cyclical) changes in the trend-chasing fund's asset allocation. The fundamental fund is acting counter-cyclically, thus functioning as a moderating force. The fund though has limited success as its average share of assets under management are, on average, only $34.6 \%$ of the total wealth.

Average turnovers of the fundamental, trend-chaser, noise trading fund are as follows (in \% of wealth under management, annualized): (a) 3.93, 4.79, 300.8; (b) 68.58, 27.56, 249.4; (c) 140.3, 36.74, 198.6. The noise trading fund indeed trades the most, followed by the fundamental fund which has a higher turnover than the trend-chasing fund due to its counter-cyclical behavior. Only in the extremely quiet market (a) is the turnover of the fundamental fund the lowest. These numbers show that being a fund investing according to fundamentals can require substantial trading volumes, mostly in building up or reducing positions to due increasing or decreasing degrees of mis-pricing. However, the turnover is only indirectly linked to the patience of clients of the fundamental fund.

The main lesson is that price volatility and severe mis-pricing are related to the degree of the fundamental fund clients' patience. As long as they are patient, noise trading has no price impact and trend-chasing funds are effectively mimicking the fundamental fund's asset allocation. Being impatient as a client of a fundamental fund makes the market vulnerable to the amplification of minor, short-term mis-pricing which leads to longer-term mis-pricing and high volatility. These market movements are caused by fundamental fund's clients moving their capital to the two pro-cyclical funds which have a better performance record over the last few periods.

\section{Conclusion}

The note illustrates that the degree of patience and its heterogeneity across investment styles matter for the market dynamics. If clients of fundamental funds are more patient than those of trend-chasing or noise trading funds, then the market is (on average) well behaved with little mis-pricing and most wealth invested according to fundamentals. However, if fundamental funds' clients are more impatient than other funds' clients, the market experiences high price volatility as well as short- and long-term mis-pricing. When fundamental investors lose trust in their asset managers when market dislocation increases (Shleifer, 2000), our results imply that their loss of patience contributes to market instability. We believe that the heterogeneous agent-based evolutionary finance market model with long-lived assets and fund-specific degrees of investors' patience presented in this note might serve as a basis for further empirical studies along the lines pursued by the applied agent-based papers referred to in the introduction. 


\section{References}

Assenza, T., Brock, W., and Hommes, C. (2017). Animal spirits, expectations, and the amplification and duration of crises. Economic Inquiry, 55:542-564.

Bogle, J. C. (2007). The Little Book of Common Sense Investing. Wiley.

Coqueret, G. (2017). Empirical properties of a heterogeneous agent model in large dimensions. Journal of Economic Dynamics and Control, 77:180-201.

Evstigneev, I., Hens, T., and Schenk-Hoppé, K. (2006). Evolutionary stable stock markets. Economic Theory, 27(2):449-468.

Evstigneev, I., Hens, T., and Schenk-Hoppé, K. R. (2009). Evolutionary finance. In Hens, T. and Schenk-Hoppé, K., editors, Handbook of Financial Markets: Dynamics and Evolution, chapter 9, pages 507-566. North Holland, Amsterdam.

Evstigneev, I. V., Hens, T., and Schenk-Hoppé, K. R. (2016). Evolutionary behavioural finance. In Haven, E., Molyneux, P., Wilson, J., Fedotov, S., and Duygun, M., editors, The Handbook of Post Crisis Financial Modelling, chapter 9, pages 214-234. Palgrave MacMillan.

Franke, G. and Lüders, E. (2010). Instability of financial markets and preference heterogeneity. Advances in Decision Sciences, Article ID 791025.

Grazzini, J., Richiardi, M. G., and Tsionas, M. (2017). Bayesian estimation of agentbased models. Journal of Economic Dynamics and Control, 77:26-47.

Harris, L. E. (2015). Trading and Electronic Markets: What Investment Professionals Need to Know. CFA Institute.

Hommes, C. (2013). Behavioral Rationality and Heterogeneous Expectations in Complex Economic Systems. Cambridge University Press.

Hommes, C. and Wagener, F. (2009). Complex evolutionary systems in behavioral finance. In Hens, T. and Schenk-Hoppé, K., editors, Handbook of Financial Markets: Dynamics and Evolution, chapter 4, pages 217-276. North Holland, Amsterdam.

Kukacka, J. and Barunik, J. (2017). Estimation of financial agent-based models with simulated maximum likelihood. Journal of Economic Dynamics \& Control, 85:21-45.

Malkiel, B. G. (2016). A Random Walk down Wall Street: The Time-tested Strategy for Successful Investing. Norton.

McCann, K. S. (2000). The diversity-stability debate. Nature, 405:228-233.

Palczewski, J., Schenk-Hoppé, K. R., and Wang, T. (2016). Itchy feet vs cool heads: Flow of funds in an agent-based financial market. Journal of Economic Dynamics and Control, 63:53-68.

Roberge, M. W., Flaherty, J. C., Almeida, R. M., and Boyd, A. C. (2013). Lengthening the investment horizon. MFS Institutional Advisors, White Paper, November.

Shiller, R. (1999). Irrational Excuberance. Princeton University Press.

Shleifer, A. (2000). Inefficient Markets: An Introduction to Behavioral Finance. Oxford University Press. 